\title{
Quantitative Analysis of Vegetation Dynamics in Response to Climatic Factors and Human Activities in Southwest China
}

Cuiping Yang ( $\nabla$ yang_cuiping@nwafu.edu.cn )

Northwest A\&F University

Yongqiang Wang

Northwest A\&F University

Jiujiang Wu

Northwest A\&F University

xiaoyi ma

Northwest A\&F University

\section{Research Article}

Keywords: Normalized difference vegetation index (NDVI), Standardized precipitation and evapotranspiration index (SPEI), driving factors, factor contribution, Sobol'global sensitivity, southwest China

Posted Date: December 27th, 2021

DOI: https://doi.org/10.21203/rs.3.rs-1165782/v1

License: (c) (i) This work is licensed under a Creative Commons Attribution 4.0 International License. Read Full License 
1 Title page

2 Quantitative analysis of vegetation dynamics in

3 response to climatic factors and human activities 


\title{
Quantitative analysis of vegetation dynamics in response to
}

\section{climatic factors and human activities in southwest China}

\author{
Cuiping Yang ${ }^{\mathrm{a}}$, Yongqiang Wang ${ }^{\mathrm{a}}$, Jiujiang $\mathrm{Wu}^{\mathrm{a}}$, Xiaoyi Ma ${ }^{\mathrm{a}, * 1}$ \\ (A Key Laboratory of Agricultural Soil and Water Engineering in Arid Area of Ministry of \\ Education, Northwest A\&F University, Yangling 712100, China)
}

\begin{abstract}
We determined the time scale of normalized difference vegetation index (NDVI) response to drought and used trend and correlation analyses to explore the spatial and temporal variability characteristics of the NDVI and SPEI and their sensitivity to climatic factors in southwest China from 2000 to 2020 . We used a partial derivative approach to calculate the contributions of six climatic factors and human activities to the interannual variation in the NDVI.
\end{abstract} The results demonstrated that from 2000 to 2020, the annual mean NDVI in southwest China showed a slight decreasing trend at a rate of $0.0001 \mathrm{y}^{-1}$. The NDVI had the highest sensitivity to the standardized precipitation and evapotranspiration index on a 12-month time scale. The NDVI exhibited a 1-year delayed response to drought. The SPEI has the highest sensitivity to precipitation. The percentage of pixels with a positive correlation between NDVI and precipitation, mean temperature, temperature difference, mean relative humidity, mean wind speed, and sunshine duration in the study area was $31.73 \%, 46.81 \%, 35.49 \%, 25.76 \%, 39.36 \%$, and $39.89 \%$, respectively. The average contributions of these six climatic factors to the interannual variation of NDVI were $0.00029,0.00046,-0.00007,0.00007,0.0008$, and $0.00001 \mathrm{y}^{-1}$, respectively. The NDVI had the highest sensitivity to mean temperature and the lowest sensitivity to mean relative humidity. The average contributions of climatic factors and human activities to interannual variability in southwest China were 0.00156 and $0.00012 \mathrm{y}^{-1}$, respectively. The positive influence of climatic factors on the NDVI was stronger than that of human activities. This study provides a theoretical basis for the sustainable management of the regional ecological environment.

Keywords: Normalized difference vegetation index (NDVI); Standardized precipitation and evapotranspiration index (SPEI); driving factors; factor contribution; Sobol' global sensitivity; southwest China

\footnotetext{
1 Author: Cuiping Yang, E-mail: yang_cuiping@nwafu.edu.cn; Corresponding author: Xiaoyi Ma, E-mail: xma@nwafu.edu.cn.
} 


\section{Introduction}

Vegetation is an important component of ecosystems (Lizaga et al., 2018; Christopher et al., 2019), with significant sensitivity to climatic factors and human activities. Vegetation growth responds to changes in environmental factors (Zhao et al., 2019). In particular, drought can affect the change in vegetation growth on a regional scale. Changes in vegetation growth have been explored to reveal the characteristics of regional ecological changes and their response mechanisms to environmental factors and human activities (Zhang et al., 2018; Nijssen et al., 2016) and to provide a theoretical basis for the formulation of reasonable ecological and environmental management policies.

The normalized difference vegetation index (NDVI) has been widely used to quantify vegetation growth and cover status. Climatic factors directly influence vegetation growth and cover change. Numerous domestic and international studies have focused on two driving factors, precipitation and temperature. Keisling et al. (2016) reported that with the gradual increase in temperature, vegetation growth at high latitudes showed early greening. Turco et al. (2016) demonstrated that the correlation coefficient between the NDVI and precipitation was high in southern Israel. Ayana et al. (2016) reported a significant correlation between NDVI values and mean precipitation in spring in eastern Africa. Mo et al. (2019 demonstrated that the growth of different types of vegetation in southwest China is increasing and is significantly influenced by environmental factors such as temperature and precipitation. Huang et al. (2016) used a distribution index to reveal significant differences in the characteristics of vegetation change between different seasons in southwest China. Han et al. (2019) and Fu et al. (2014) determined that the annual mean NDVI values in southwest China exhibited an increasing trend and were significantly correlated with both temperature and precipitation. The influence of climatic factors on evapotranspiration has been evaluated based on the partial derivative method, which quantifies the contribution of each driving factor (Yang et al., 2012; Meng et al., 2012). In addition to precipitation and temperature, the contribution of other drivers of climatic factors (relative humidity, solar radiation and wind speed) to vegetation growth is undisputed, but unfortunately, there are fewer relevant studies in this area.

Vegetation growth is more sensitive to climatic factors than human activities (Mu et al., 2013). 
And the impact of human activities on vegetation growth varies from region to region. And vegetation growth in southwest China correlated best with autumn precipitation and summer temperatures and that human activities contributed to vegetation growth ( $\mathrm{Li}$ et al., 2015). The impact of human activities on the vegetation of the Loess Plateau and Qinling Mountains was demonstrated to be two-sided, but the positive effects were greater than the negative effects (Shi et al., 2020; Liu et al., 2016). The effects of human activities and vegetation growth are reciprocal, with urbanization leading to a decrease in the area of suburban vegetation on the one hand and an increase in the area of urban greenery on the other (Yao et al., 2018; Gong et al., 2017). Analysis of residuals is commonly used in such studies to analyze the relationship between vegetation and drivers, but this method cannot accurately quantify the contribution of climatic factors and human activities to vegetation, especially in distinguishing and comparing the effects of individual climatic factors on vegetation, while the partial derivative method can compensate for this shortcoming (Qu et al., 2018; Yan et al., 2019).

The study of vegetation change characteristics in southwest China is crucial for ecological security. Current studies mainly focus on vegetation cover change monitoring and attribution; studies on the influence of climatic factors on the NDVI mainly concern the influence of temperature and precipitation on the NDVI. Few studies have been conducted to separately quantify each driver affecting regional vegetation growth. Therefore, the purpose of this paper is to explore (1) temporal variations of the NDVI, the standardized precipitation and evapotranspiration index (SPEI), and climatic factors from 2000 to 2020; (2) response characteristics of vegetation to drought on different time scales; (3) the sensitivity of interannual variation trend of NDVI to climatic factors in southwest China from 2000 to 2020; and (4) the contributions of six climatic factors and human activities to the interannual variation of the NDVI based on the partial derivative method. This study provides a scientific basis for the planning of ecological projects in southwest China by elucidating the response mechanisms of vegetation dynamics to drought on different time scales and quantifying the contribution of different drivers to the NDVI.

\section{Materials and methods}

\subsection{Study region}

Southwest China includes Yunnan Province, Guizhou Province, Sichuan Province, Guangxi 
Zhuang Autonomous Region, and Chongqing Municipality, with an area of approximately $1.37 \times$ $10^{6} \mathrm{~km}^{2}$ (Fig. 1). The region is located between $20^{\circ} 54^{\prime}-34^{\circ} 19^{\prime} \mathrm{N}$ and $97^{\circ} 21^{\prime}-112^{\circ} 04^{\prime} \mathrm{E}$. The western, northwestern, and central-eastern parts of the study region are mountainous and hilly and account for more than two-thirds of the total area of the region. The rest of the region is mostly plains and plateau. The region is in the climate transition zone of the Qinghai-Tibet Plateau, with a generally warm and sunny climate. The average annual temperature is $14-24{ }^{\circ} \mathrm{C}$ and the average annual precipitation is $600-2300 \mathrm{~mm}$, with precipitation mainly concentrated in the summer and autumn (80\%-90\%; Zhao, 1997). Precipitation is largely characterized by a decreasing distribution from the southeast to northwest (Zhu et al., 2017), ranging from more than $2500 \mathrm{~mm}$ on the northern coast of the Beibu Gulf (Guangxi Zhuang Autonomous Region) to less than $700 \mathrm{~mm}$ in northwestern and northeastern Yunnan (Li et al., 2019).

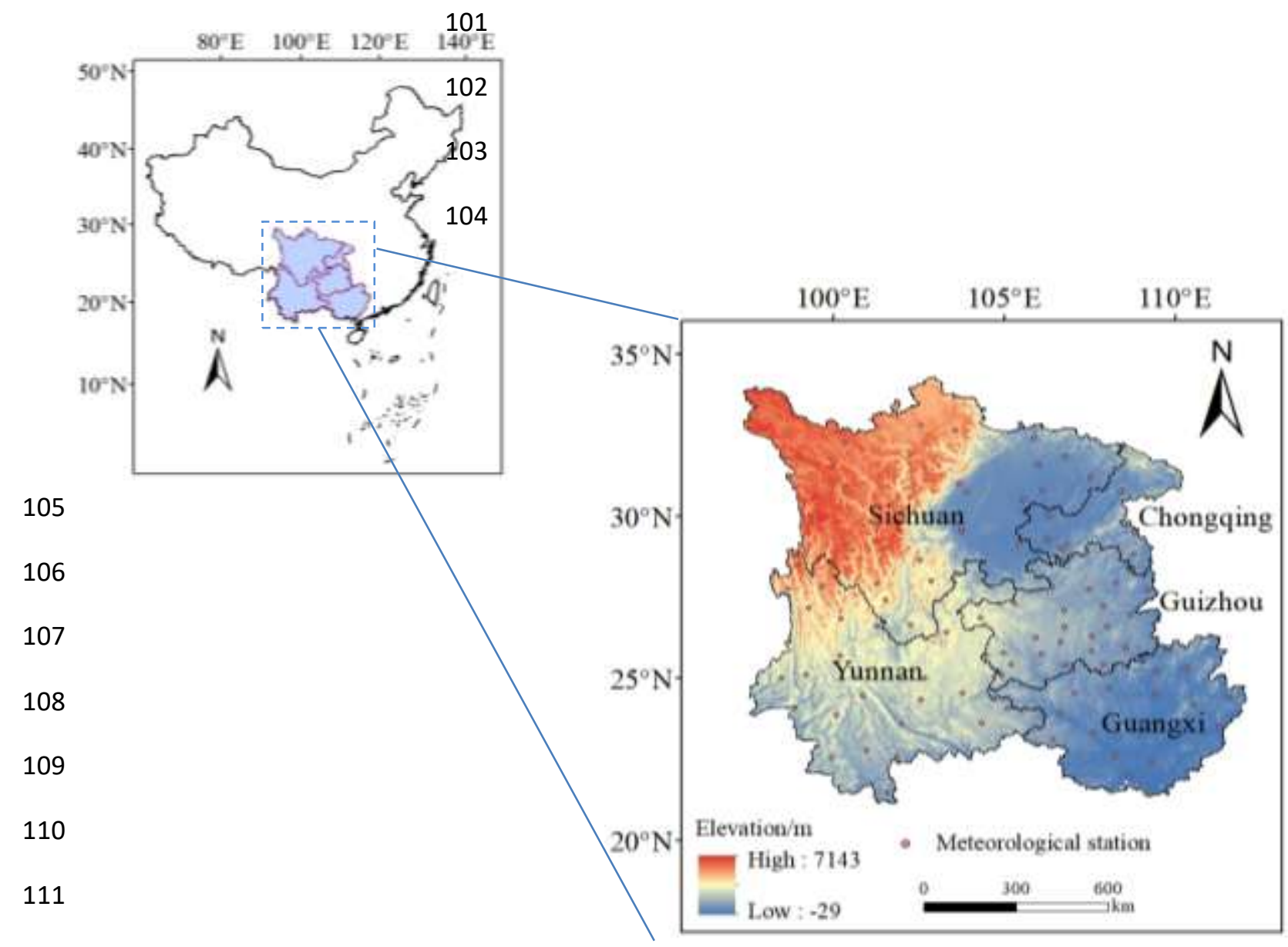

Fig. 1 The study region comprises four provinces, Yunnan, Guizhou, Sichuan, and Guangxi, and a municipality, Chongqing. 


\subsection{Data source and processing}

\subsubsection{Meteorological data}

Meteorological data were obtained from 108 meteorological station datasets provided by the China Meteorological Data Sharing Service Center (http://cdc.cma.gov.cn). Datasets included daily precipitation, maximum temperature, minimum temperature, average wind speed, light hours, and average relative humidity data from 2000 to 2020. Datasets from 32 stations that had data missing for more than one year were excluded; the remaining 96 stations were distributed as shown in Fig 1. To facilitate the correlation analysis between the NDVI and SPEI, the SPEI calculated using station meteorological data was interpolated as raster data using inverse distance weights, with the spatial resolution resampled to $1 \mathrm{~km}$.

\subsubsection{Remote sensing data}

MODIS NDVI data were derived from the MOD13Q1 dataset (https://lpdaac.usgs.gov/products/ mod13q1v006/) from the MODIS Terra satellite sensor data from 2000 to 2020. The spatial resolution was $500 \mathrm{~m}$ and the temporal resolution was $16 \mathrm{~d}$. NDVI data were synthesized into monthly values using the maximum value composite method (Cong et al., 2012; Zhao et al., 2017). The NDVI data were also resampled to a spatial resolution of $1 \mathrm{~km}$.

\subsection{Methods}

\subsubsection{NDVI}

As an important remote sensing parameter reflecting vegetation status, NDVI is an indicator of plant growth status and spatial distribution density. The NDVI was defined as follows:

$$
N D V I=\frac{N I R-R E D}{N I R+R E D}
$$

where $N I R$ is the near-infrared reflectance and RED is the visible reflectance. Regions with an NDVI $>0.1$ are generally considered vegetated, and an increase in NDVI indicates an increase in green vegetation; an NDVI $<0.1$ indicates the lack of detectable vegetation on the surface, which could mean human settlement, bare soil, desert, water bodies, or clouds.

\subsubsection{SPEI}

Vicente-Serrano et al. (2010) proposed the SPEI. Compared with the standardized precipitation index, the SPEI considers the effect of potential evapotranspiration and uses the FAO 
Penman-Monteith formula to calculate potential evapotranspiration $\left(E T_{0}\right)$, which can more

144

145

146

147

148

149

150

151

152

153

154

155

156

157

158

159

160 accurately characterize the drought condition, especially in regions with significant warming (Zhang et al., 2015). The specific calculation method is found in Ruspini et al. (1965).

\subsubsection{Trend analysis}

To quantitatively reflect the spatial and temporal variation of the NDVI in the study region, interannual trends in the NDVI were calculated at the pixel level using least squares regression, and the F-test was used to determine the significance of each pixel. The calculation equation was as follows:

$$
\lambda_{\text {slope }}=\frac{n \sum_{i=1}^{n} i \times C_{i}-\sum_{i=2}^{n} i \sum_{i=1}^{n} C_{i}}{n \sum_{i=1}^{n} i^{2}-\left(\sum_{i=1}^{n} i\right)^{2}}
$$

where $\lambda_{\text {slope }}$ is the slope of regression, $n$ is the total number of years monitored $(n=21)$, and $C_{i}$ is the mean NDVI value in year $i$. When $\lambda_{\text {slope }}>0$, the NDVI had an increasing trend during the study period; otherwise, it had a decreasing trend.

\subsubsection{Correlation analysis}

The correlation between NDVI and SPEI and the correlation between NDVI and climate factors were evaluated by calculating Pearson correlation coefficients of all pixels. The calculation equation was as follows:

$$
R=\frac{\sum_{i=1}^{n}\left(x_{i}-\bar{x}\right)\left(y_{i}-\bar{y}\right)}{\sqrt{\sum_{i=1}^{n}\left(x_{i}-\bar{x}\right)^{2} \sum_{i=1}^{n}\left(y_{i}-\bar{y}\right)^{2}}}
$$

where $x_{i}$ and $y_{i}$ represent the values of the SPEI (or climatic factors) and the NDVI in year $i$, respectively, and $x$ and $y$ are the average values of the SPEI (or climatic factors) and the NDVI over time.

\subsubsection{Sobol' sensitivity analysis of the SPEI to climatic factors}

In this study, the Sobol global sensitivity analysis method (Aovk, et al., 2017), which analyzes the independent and total sensitivity of the SPEI to meteorological factors, was selected as a global 
sensitivity analysis method based on variance assignment. The model is first decomposed as a 168 function of individual variables and combinations between variables, and then, the total variance 169 of the model output is decomposed as a combination of individual input variables and correlations between variables as follows:

$$
V=\sum_{i} V_{i}+\sum_{i<j} V_{i j}+\sum_{i<j<m} V_{i j m}+\Lambda V_{1,2, \Lambda, k}
$$

where $V$ is the total variance value of the model output, $V_{i}$ is the variance value caused by the input variables, and $V_{i j}$ is the variance value caused by the correlation between the input variables $i$ and $j$.

The formula for calculating the sensitivity coefficient is as follows:

where Eq. (5) is used to calculate the first-order sensitivity coefficient, which represents the independent sensitivity of SPEI to meteorological factors, Eq. (6) is used to calculate the second-order sensitivity coefficient, which represents the correlation between meteorological factors, and Eq. (7) is used to calculate the total order sensitivity coefficient, which represents the total sensitivity of the SPEI to meteorological factors. The variance of these equations was estimated by approximating Monte Carlo values. $S_{P r e}, S_{T e m}, S_{T \max -T m i n}, S_{R h}, S_{W s}$, and $S_{S d}$ represent the sensitivity coefficients of the SPEI to precipitation, mean temperature, temperature difference, mean relative humidity, mean wind speed, and sunshine duration, respectively.

\subsubsection{Contribution of each driver to the interannual variation of the NDVI}

The partial derivative method has been widely used to quantify the contribution of climatic factors to evapotranspiration (Meng et al., 2012; Li et al., 2017a). It is increasingly applied to vegetation analysis (Yan et al., 2019; Zhang et al., 2016). We applied this method to quantitatively estimate 
the contribution of different drivers to changes in the NDVI. We assumed that climatic factors (precipitation, average temperature, temperature difference, average relative humidity, average wind speed, and sunshine duration) and nonclimatic factors are the complete set of environmental factors that contribute to NDVI variation. The contribution of each factor to the interannual variability of NDVI was calculated as follows:

$\lambda_{\text {slope }}=\operatorname{Con}(\operatorname{Pre})+\operatorname{Con}(\mathrm{Tem})+\operatorname{Con}(T \max -T \min )+\operatorname{Con}(R h)+\operatorname{Con}(W s)+\operatorname{Con}(S d)+U F$ $=\frac{\partial N D V I}{\partial P r e} \times \frac{\partial \operatorname{Pr} e}{\partial t}+\frac{\partial N D V I}{\partial T e m} \times \frac{\partial T e m}{\partial t}+\frac{\partial N D V I}{\partial T \max -T \min } \times \frac{\partial T \max -T \min }{\partial t}+\frac{\partial N D V I}{\partial R h} \times \frac{\partial R h}{\partial t}+$ $\frac{\partial N D V I}{\partial W s} \times \frac{\partial W s}{\partial t}+\frac{\partial N D V I}{\partial S d} \times \frac{\partial S d}{\partial t}+U F$ $=C F+U F$

where $\lambda_{\text {slope }}$ is the interannual variability of NDVI, which is obtained from Equation (2), and precipitation, mean temperature, temperature difference, mean relative humidity, mean wind speed, and sunshine duration are expressed by Pre, Tem, Tmax - Tmin, Rh, Ws, and $S d$, respectively. Con(Pre), Con(Tem), Con(Tmax - Tmin), Con (Rh), Con(Ws), and Con(Sd) denote the contributions of precipitation, mean temperature, temperature difference, mean relative humidity, mean wind speed, and sunshine duration to the interannual variation of the NDVI, respectively; $t$ is time. $\frac{\partial N D V I}{\partial T e m}, \frac{\partial N D V I}{\partial T \max -T \min }, \frac{\partial N D V I}{\partial R h}, \frac{\partial N D V I}{\partial W s} \frac{\partial N D V I}{\partial S d}$ denote the slopes of linear regressions between the NDVI and precipitation, mean temperature, temperature difference, mean relative humidity, mean wind speed, and sunshine duration, respectively. $\frac{\partial \operatorname{Pr} e}{\partial t}, \frac{\partial T e m}{\partial t}, \frac{\partial T \max -T \min }{\partial t}, \frac{\partial R h}{\partial t}, \frac{\partial W s}{\partial t}, \frac{\partial S d}{\partial t}$ denote the slope of linear regression of precipitation, mean air temperature, temperature difference, mean relative humidity, mean wind speed, and sunshine duration at time $t$, respectively. $C F$ and $U F$ denote the contributions of climatic and nonclimatic factors to the interannual variability of the NDVI, respectively, where $C F$ is the sum of $\operatorname{Con}(\operatorname{Pre}), \operatorname{Con}(\operatorname{Tem}), \operatorname{Con}(\operatorname{Tmax}-\operatorname{Tmin}), \operatorname{Con}(R h), \operatorname{Con}(W s)$, and $\operatorname{Con}(\operatorname{Sd})$, and $U F$ is the residual between the rate of NDVI change and the contribution of climatic factors. In this study, the contribution of other unknown natural factors was ignored, and $U F$ was considered to be the contribution of human activities to the NDVI. A positive contribution of the driver to the 
interannual variation of the NDVI indicated that the driver promoted an increase in the NDVI.

\section{Results and analysis}

216

\subsection{Temporal variation of climatic factors and drought indices in southwest China}

217

The results of the linear trend analysis demonstrated that the mean NDVI value in southwest

China decreased slightly with a slope of -0.0001 from 2000 to 2020 ; the NDVI curve fluctuates

widely, with the minimum value of 0.36 appearing in 2012 (Fig. 2). The slope of the SPEI was

0.0037, which indicates a slightly wet trend in the climate of the southwest between 2000 and 221 2020 , with the minimum value of -0.66 occurring in 2011 . Based on the time of the minimum values of the NDVI and SPEI, the NDVI response to drought lagged by up to 1 year. The mean values of precipitation, mean temperature, temperature difference, mean relative humidity, mean

wind speed, and sunshine duration in the southwest from 2000 to 2020 were $1142.33 \mathrm{~mm}$, $15.94{ }^{\circ} \mathrm{C}, 9.48{ }^{\circ} \mathrm{C}, 73.39 \%, 1.64 \mathrm{~m} \mathrm{~s}^{-1}$, and $1606.96 \mathrm{~h}$, respectively. Mean temperature and mean wind speed exhibited a significant increasing trend $(P<0.05)$, with increases of $0.0222{ }^{\circ} \mathrm{C} \mathrm{y}^{-1}$ and $0.00171 \mathrm{~m} \cdot \mathrm{s}^{-1} \cdot \mathrm{y}^{-1}$, respectively. Precipitation, mean relative humidity, and sunshine duration 228 exhibited a nonsignificant increasing trend $(P>0.05)$, with increases of $4.3316 \mathrm{~mm} \mathrm{y}^{-1}, 0.0086 \%$ $\mathrm{y}^{-1}$, and $0.3031 \mathrm{~h} \cdot \mathrm{y}^{-1}$, respectively. Temperature difference exhibited a decreasing trend, with a 230 increasing trend. The temperature change in southwest China responded to the global warming trend. 

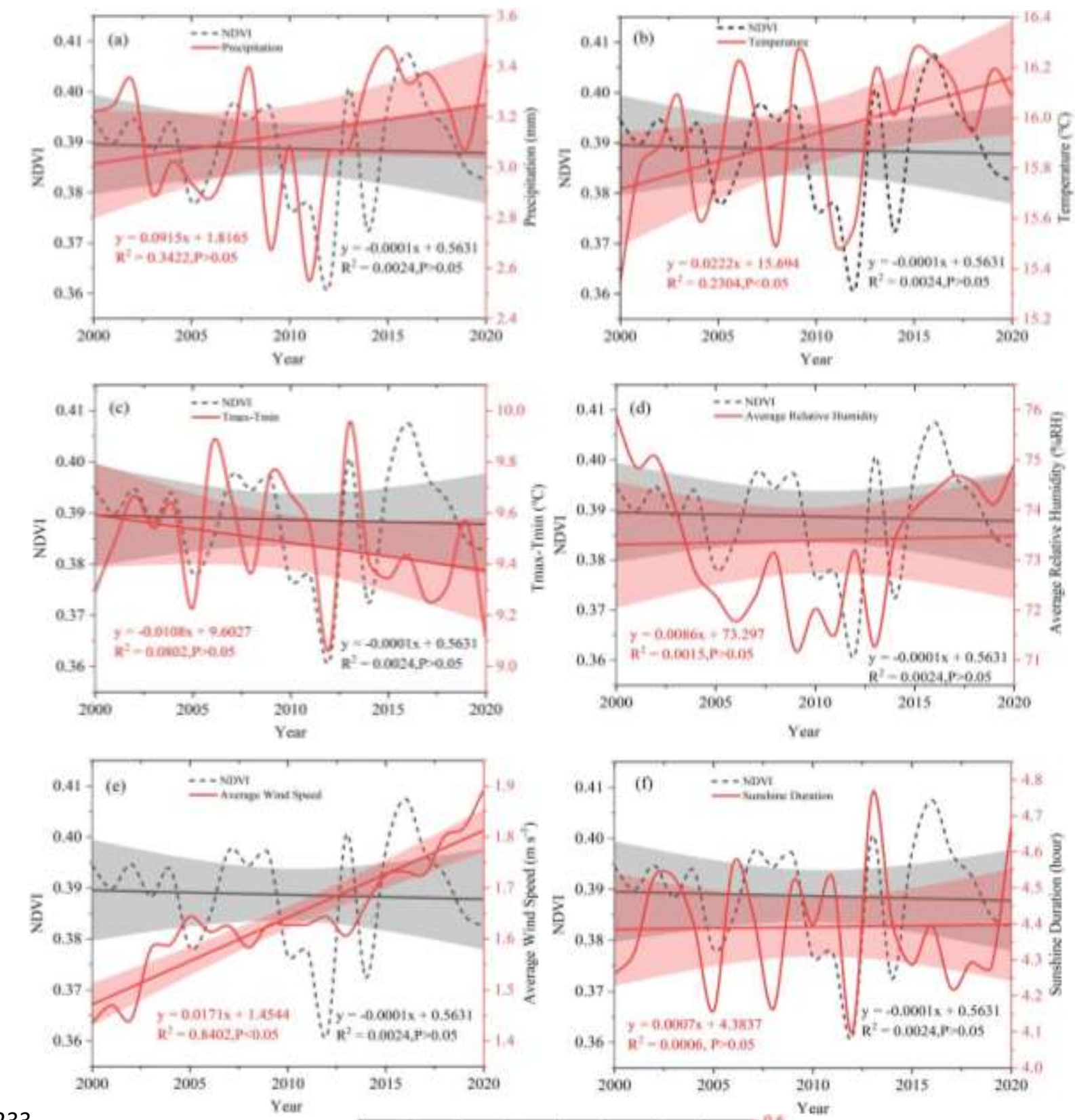

234

235

236

237

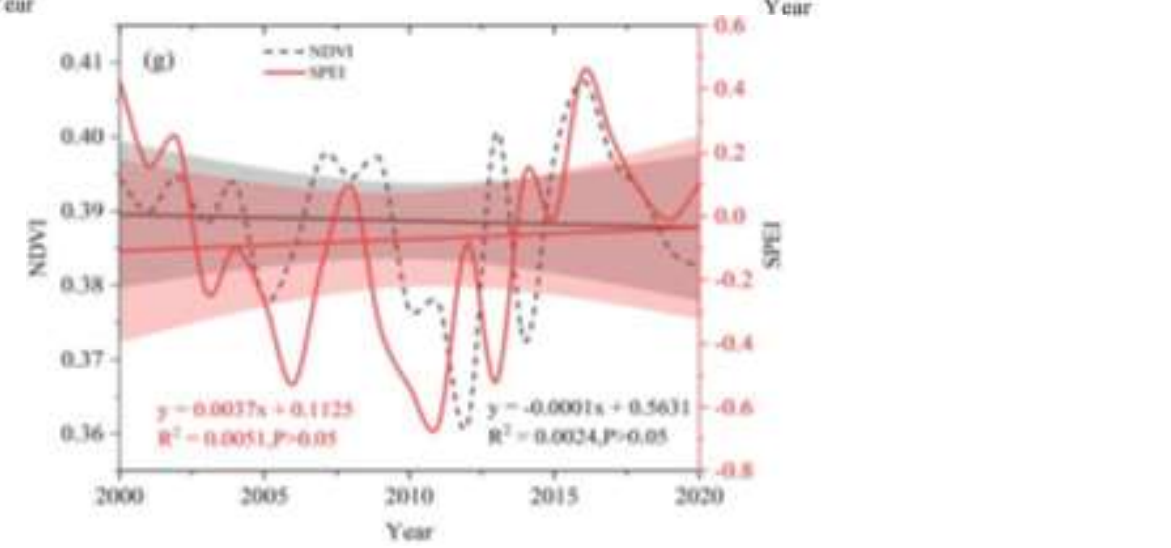


Fig. 2 Trends of the normalized difference vegetation index (NDVI), climatic factor, and standardized precipitation and evapotranspiration index (SPEI) changes in southwest China from 2000 to 2020 . The shaded areas indicate the confidence intervals of the NDVI, climatic factor, and

\subsection{Response of the NDVI to the SPEI on different time scales}

Fig. 3 illustrates the spatial pattern of the correlation between the NDVI and SPEI on different time scales in southwest China from 2000 to 2020. The correlation coefficients between the NDVI and SPEI were significantly spatially heterogeneous across the study area, but the correlations between the NDVI and SPEI on different time scales were spatially homogenous. The areas with high correlation coefficients between the NDVI and SPEI were located primarily in northeastern Sichuan Province, Chongqing City, eastern Yunnan Province, and central Guangxi Province, with a maximum value of 0.91 , whereas the areas with low correlation coefficients were located primarily in western Sichuan Province and western Yunnan Province (Hengduan Mountains), with a minimum value of -0.51 . Overall, the highest correlation between the NDVI and drought in southwest China was in the central region, followed by the eastern and western regions. The proportion of pixels that passed the significance test for the correlation between the NDVI and the SPEI on the time scales of 1 month (SPEI-1), 3 months (SPEI-3), 6 months (SPEI-6), and 12 months in southwest China was $5.93 \%, 6.20 \%, 7.44 \%$, and $9.89 \%$, indicating that the correlation between vegetation growth and wet and dry conditions in these regions was high. The sensitivity of the NDVI to SPEI-12 was the highest, and the time scale of the response to drought was longer. 

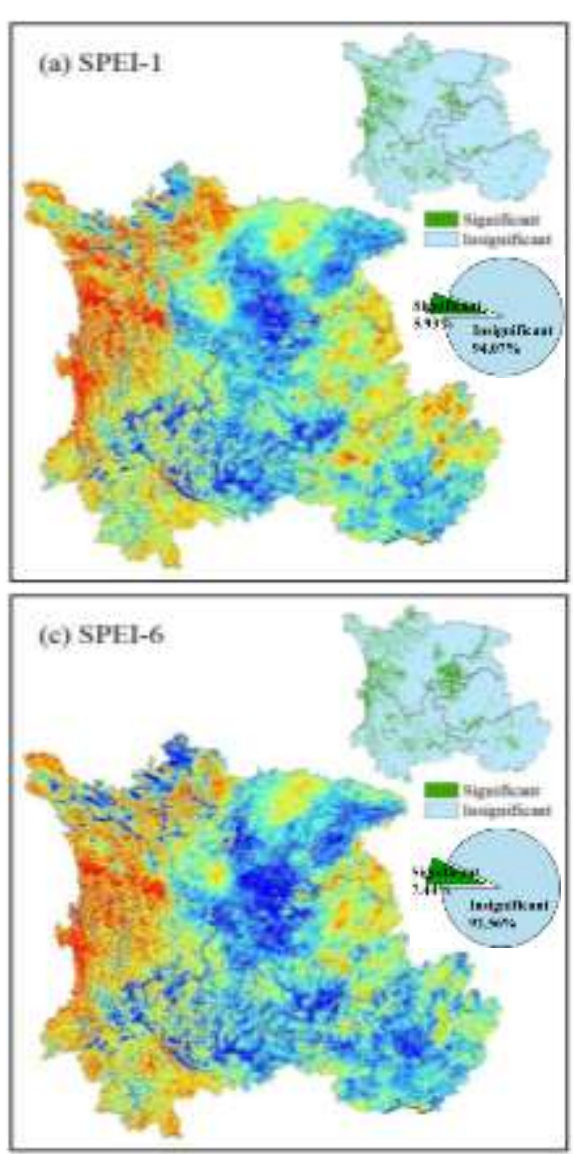

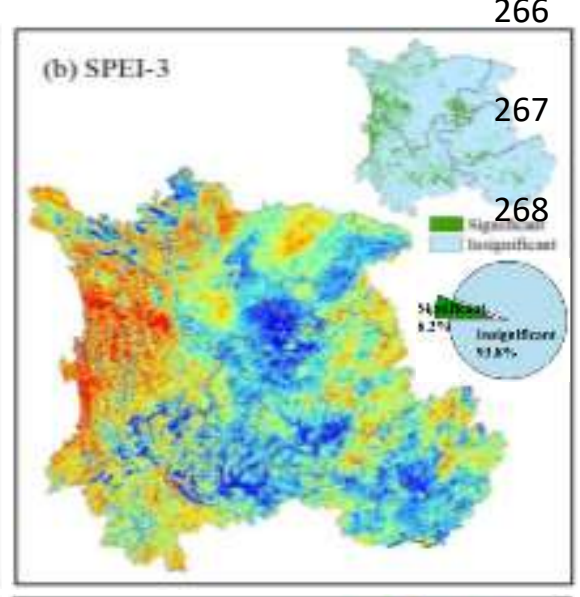

(d) SPE-12

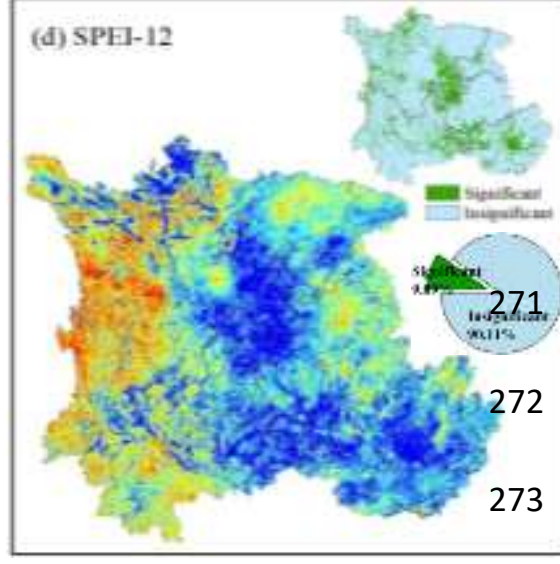

Correlartion coefficient

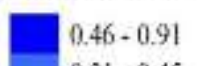

$0.31 \cdot 0.45$

$0.18-0.3$

$0.06-0.17$

$-0.06-0.05$

$-0.19--0.07$

$-0.33-0.2$

$-0.5-0.34$

270

Fig. 3 Correlation coefficients of the normalized difference vegetation index (NDVI) with the

standardized precipitation and evapotranspiration index (SPEI) of different time scales in southwest China from 2000 to 2020. (a-d) The correlation coefficients of the NDVI with the SPEI on the time scales of 1 month (SPEI-1), 3 months (SPEI-3), 6 months (SPEI-6), and 12 months (SPEI-12). The inset in the upper right corner shows the regions in the southwest that passed the significance test $(P<0.05)$ for the pixel class. The pie inset shows the proportion of pixel area $(\%)$ that passed the significance test for the correlation analysis of the NDVI and SPEI.

\subsection{Sensitivity analysis of SPEI and NDVI to climate factors in southwest China}

\subsubsection{Global sensitivity analysis of SPEI to climate factors}

To further investigate the influence of climatic change on vegetation, this study used the Sobol' global sensitivity method to analyze the sensitivity of the SPEI to precipitation, mean temperature, temperature difference, mean relative humidity, mean wind speed, and sunshine duration in southwest China (Fig. 4). We determined that the first-order sensitivity and total sensitivity 
coefficients of the relationship between the SPEI and the six climatic factors were nearly identical,

that is, the SPEI had the highest sensitivity to precipitation, followed by average relative humidity,

and the lowest sensitivity to sunshine duration. The maximum value of 0.45 of the first-order

precipitation sensitivity coefficient occurred in July and the minimum value of 0.06 occurred in February, indicating a considerable seasonal difference. The difference between the total intra-annual sensitivity coefficients and the first-order sensitivity coefficients of precipitation, mean air temperature, temperature difference, mean relative humidity, mean relative wind speed, and sunshine duration was $0.54,0.54,0.31,0.42,0.12$, and 0.09 , respectively, indicating that the SPEI was more sensitive to the effects of average temperature and precipitation and the least

sensitive to sunshine hours, which differs from the sensitivity of the NDVI to individual climatic factors. This demonstrates that the constraint affecting drought in the study area was precipitation.
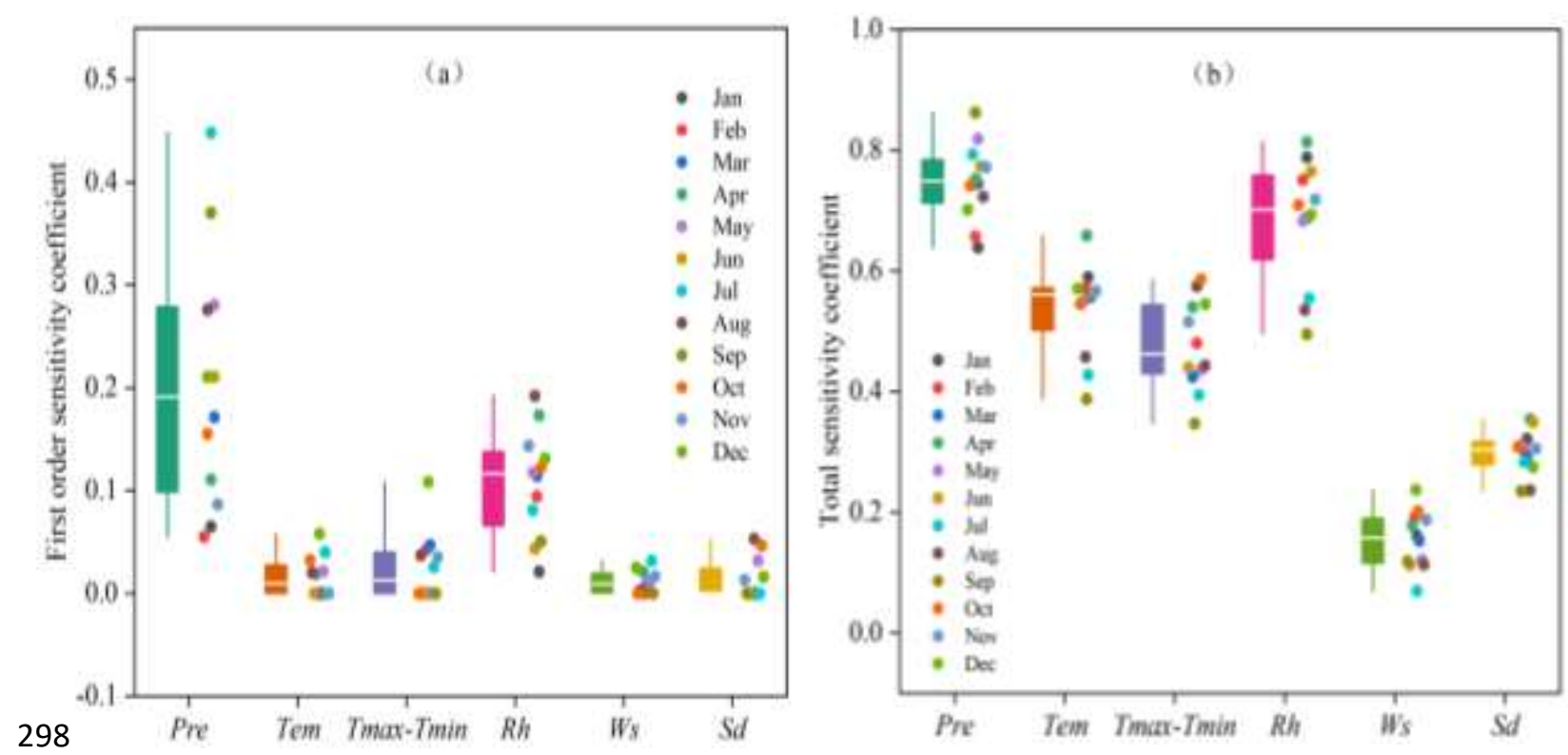

Fig. 4 Intra-annual variation of first-order sensitivity and total sensitivity of the standardized

precipitation and evapotranspiration index to climatic factors in southwest China

( Pre[precipitation]; Tem[mean temperature]; Tmax - Tmin [temperature difference]; $R h$ [mean relative humidity]; Ws [mean wind speed]; $S d$ [sunshine duration])

\subsubsection{Sensitivity of the NDVI to climatic factors}

A combination of factors affects the healthy growth of vegetation. Both climate change and land use change are key factors affecting the spatial and temporal patterns of vegetation growth (Mao et 
al., 2012). We analyzed the correlation between the NDVI and climatic factors (Fig. 5). Positive 306 and negative correlations between the NDVI and precipitation, mean air temperature, temperature 307 difference, mean relative humidity, mean relative wind speed, and sunshine duration coexisted; the 308 proportion of pixels with positive correlations between the NDVI and the six climatic factors in the study area was $31.73 \%, 46.81 \%, 35.49 \%, 25.76 \%, 39.36 \%$, and $39.89 \%$, respectively, which indicates that the NDVI was most sensitive to mean temperature, followed by sunshine hours; the NDVI was least sensitive to mean relative humidity. Therefore, temperature was the most important factor limiting vegetation growth in southwest China during the study period. The proportion of pixels that passed the significance test $(P<0.05)$ for the correlation between the NDVI and precipitation, mean air temperature, temperature difference, mean relative humidity, mean relative wind speed, and sunshine duration in the study area was $6.93 \%, 15.69 \%, 8.31 \%$, $5.85 \%, 16.06 \%$, and $6.67 \%$, respectively. The areas of high correlation between the NDVI and temperature were located primarily in southeastern Sichuan, western Guizhou, and southern Guangxi, with a wide distribution; northwestern Sichuan (Ruoerge Plateau) is at a high altitude with low vegetation cover, so the correlation with temperature was low. The influence of precipitation on the NDVI in the study area was relatively small, which is a result of the differing surface vegetation cover and elevation topography in the southwest and the large difference in precipitation correlation. The regions with a significant correlation $(P<0.05)$ between mean annual NDVI and mean annual precipitation were mainly located in southeastern Sichuan and northeastern Yunnan (central and western Yunnan-Guizhou Plateau), which is explained by the fact that in mountainous or humid areas where precipitation is abundant, the water conditions required for plant growth can be met, whereas excessive precipitation can reduce light and affect photosynthesis, thus affecting plant growth (Li et al., 2009). By contrast, the correlation between the NDVI and precipitation was lower in the Sichuan basin than in the surrounding areas because the region is an agricultural area where crops are well watered because of irrigation and other tillage practices and require less natural precipitation. The areas with a high correlation between 
the NDVI and mean wind speed were mainly in northeastern Sichuan (Sichuan Basin), which is related to the special topography of the basin. The NDVI was significantly correlated with 333 sunshine duration mainly in Guizhou Province The correlation between the NDVI and mean 334 relative humidity was negative in most areas.

335
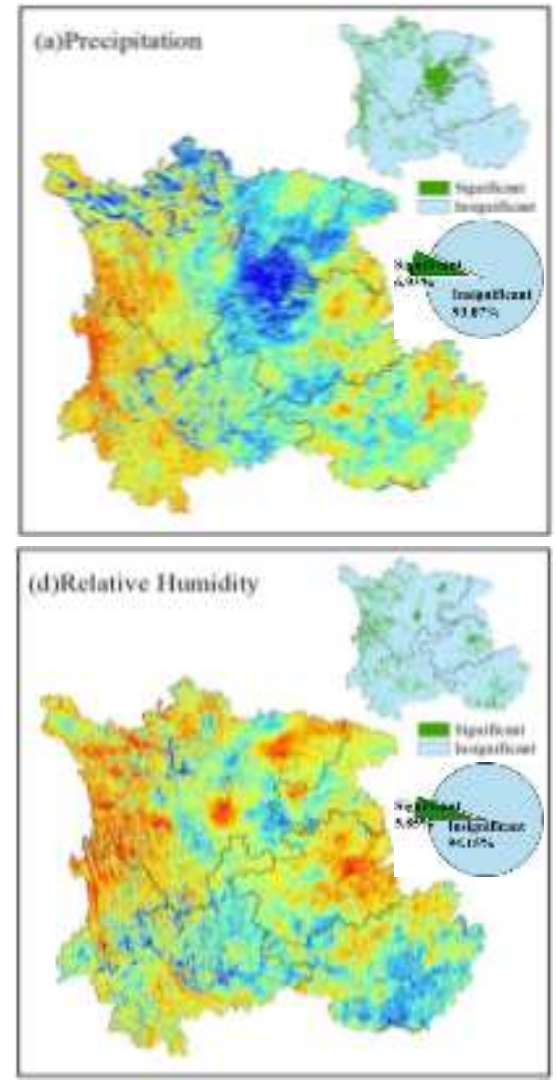

337

338

339

340

341

342

343

344 8
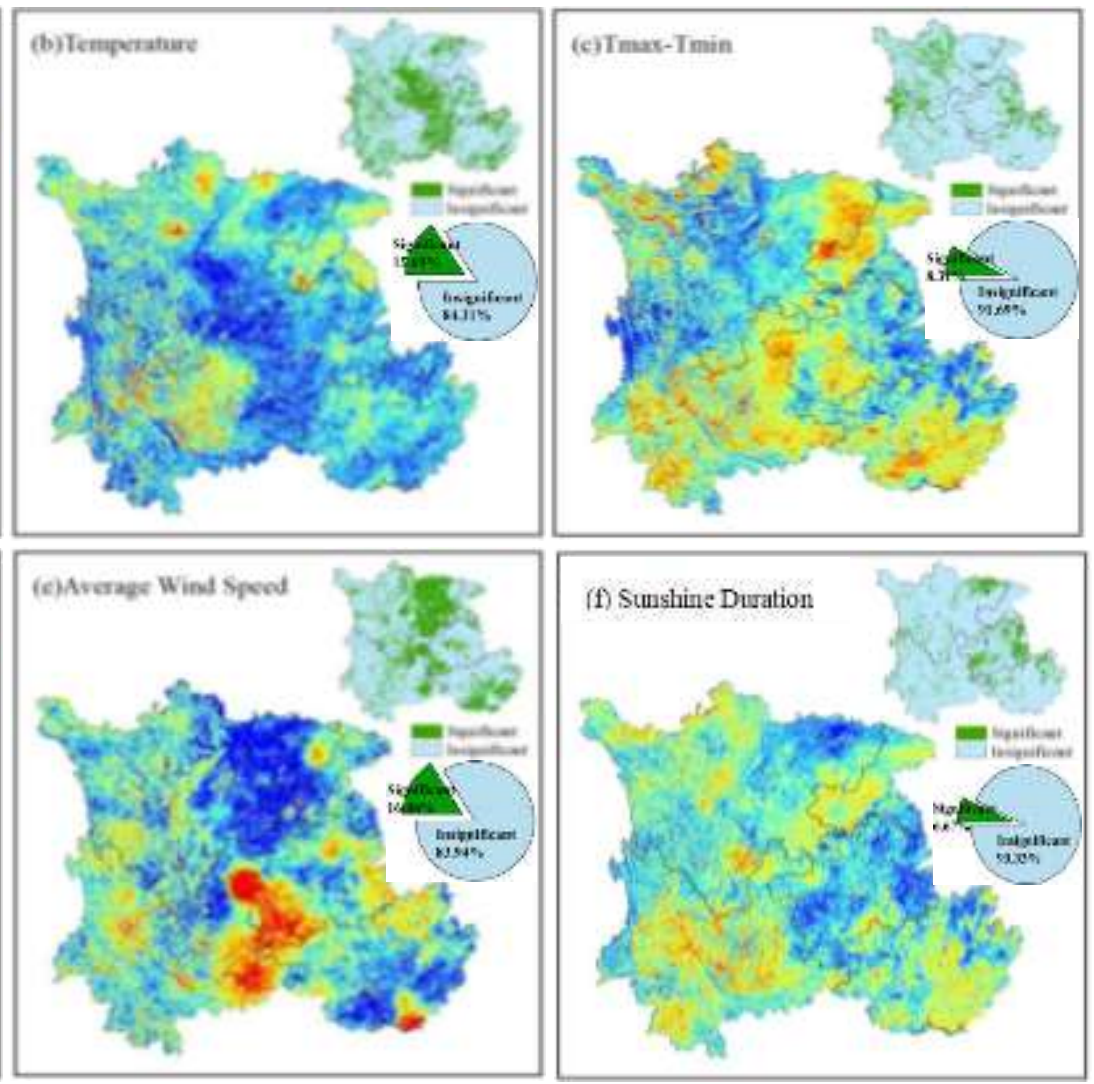

Correlation coefficient

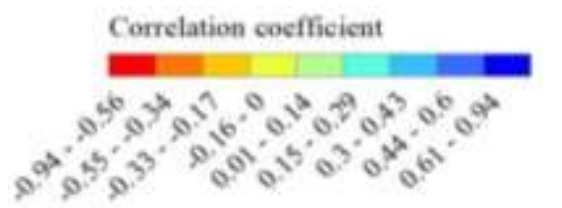

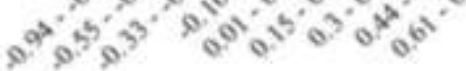

$$
\text { . }
$$


correlation analysis of the NDVI and climatic factors. The pie inset shows the proportion of pixel areas $(\%)$ that passed the significance test.

\subsection{Quantitative analysis of the drivers of vegetation dynamics in southwest China}

\subsubsection{Contribution of climatic factors to the interannual variation of the NDVI}

The correlation coefficients describe the sensitivity of vegetation to climatic factors but cannot quantify the effect of climatic factors on the interannual variation of the NDVI. To quantify the effects of climatic factors on the NDVI, this study compared the contributions of each climatic factor to the NDVI of southwest China from 2000 to 2020 at the regional and pixel levels (Fig. 6) and analyzed the relationships between the NDVI, each climatic factor, and human activities. The average contributions of the six climatic factors to the NDVI were mainly positive. The average contributions of precipitation, average temperature, temperature difference, average relative humidity, average wind speed, and sunshine duration to the NDVI were $0.00029,0.00046$, $-0.00007,0.00007,0.0008$, and $0.00001 \mathrm{y}^{-1}$, respectively. Mean wind speed contributed the most to the NDVI, followed by mean temperature and precipitation; the mean contribution of temperature difference to the NDVI was negative. At the pixel level, the positive contributions of precipitation, mean temperature, temperature difference, mean relative humidity, mean wind speed, and sunshine duration to the interannual variation of the NDVI were $45.24 \%, 53.39 \%, 32.79 \%$, $38.83 \%, 52.45 \%$, and $34.07 \%$, respectively, for the study area, which indicated a strong positive contribution of temperature to the NDVI. And we determined that temperature difference and sunshine hours had the strongest negative contributions to the NDVI for the southeastern part of southwest China (Guizhou and Guangxi provinces). Mean wind speed made the largest contribution to the interannual variation of the NDVI in northeastern Sichuan, with a maximumvalue of $0.0139 \mathrm{y}^{-1}$. Precipitation made a relatively small contribution to the NDVI in southwest China. In conclusion, the NDVI in southwest China was most sensitive to temperature and relatively sensitive to mean wind speed and precipitation. 


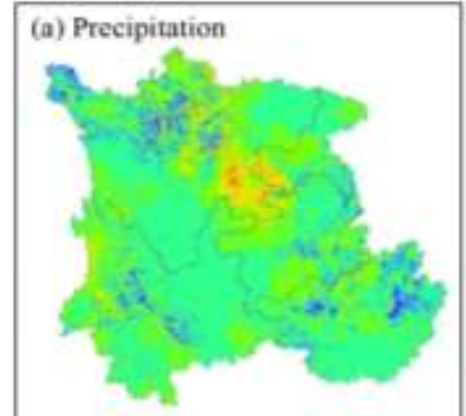

(d) Average Relative Humidity
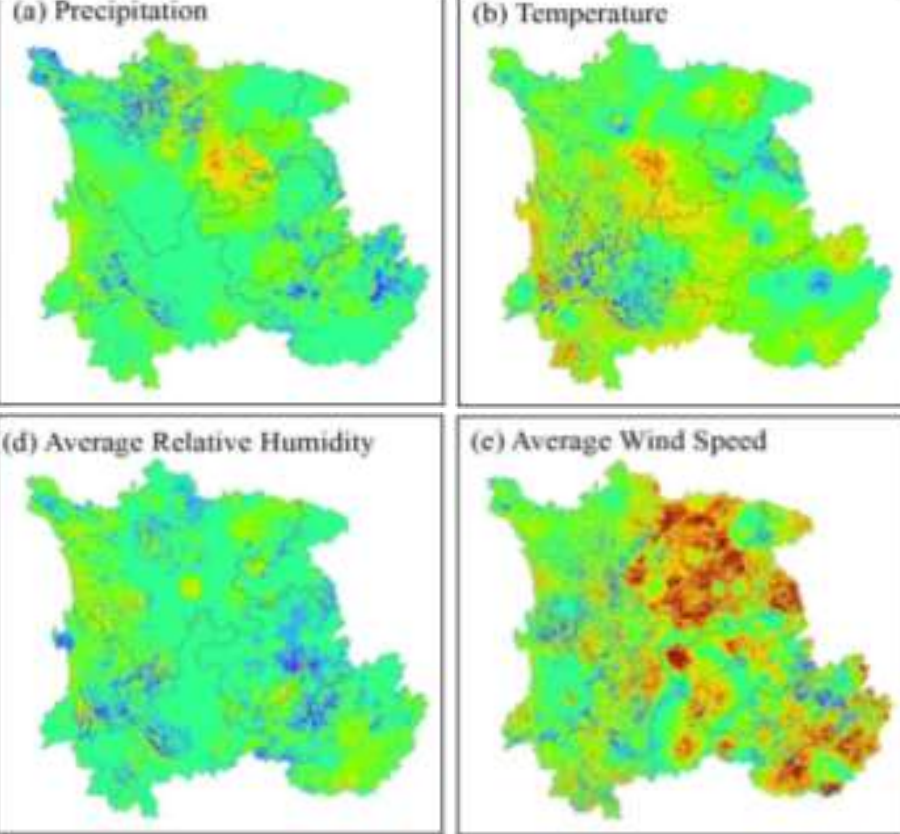

(c) Average Wind Speed

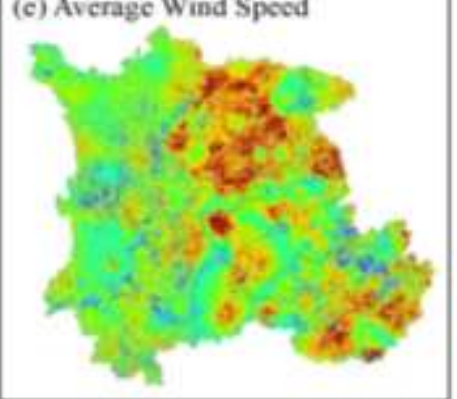

Factor sontribution

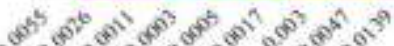

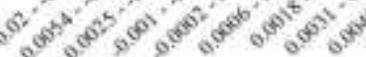

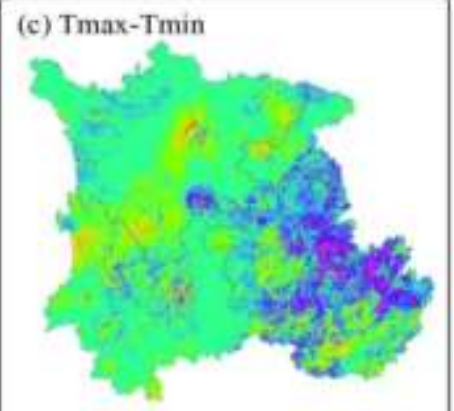

(f) Sunshine Duration

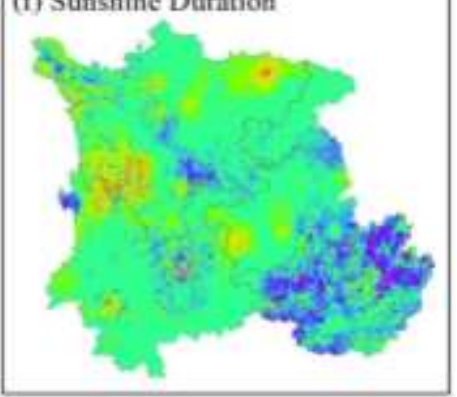

Fig. 6 Contribution of climatic factors to the interannual variation of the NDVI in southwest China

from 2000 to 2020 . 
The total contribution of climatic and nonclimatic factors to the interannual variation of the NDVI 380 in southwest China is illustrated in Fig. 7. The interannual rate of change of the NDVI in 381 southwest China from 2000 to 2020 was $0.00168 \mathrm{y}^{-1}$, of which the contribution of climatic factors 382 was $0.00156 \mathrm{y}^{-1}$ and that of $U F$ was $0.00012 \mathrm{y}^{-1}$, which indicates that both climatic and 383 nonclimatic factors had a positive influence on the NDVI. Climatic factors mainly contributed to 384 the NDVI in eastern Sichuan and southern Guangxi, regions which are mostly flatter crop-growing 385 areas sensitive to climatic factors. The contribution from climatic factors was relatively small for 386 northwestern Sichuan (Ruoerge Plateau). Pixels in which climatic factors and human activities 387 made positive contributions to the NDVI in southwest China accounted for $80.52 \%$ and $52.49 \%$ of 388 the region, respectively. The positive influence of climatic factors on the NDVI was stronger than 389 that of human activities.

390
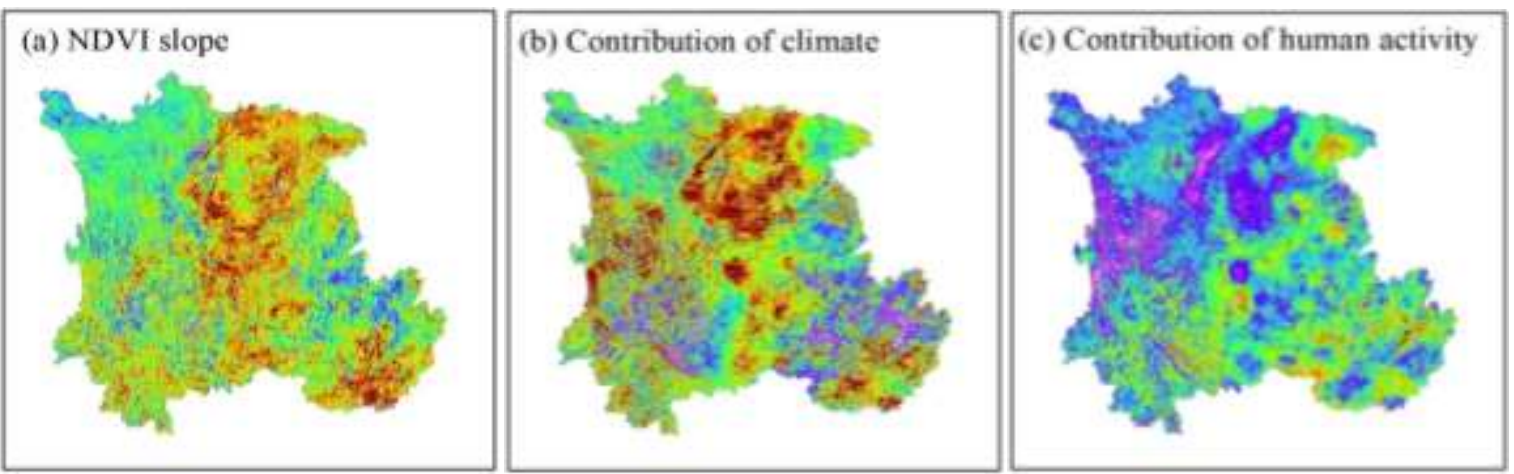

Factor contribution

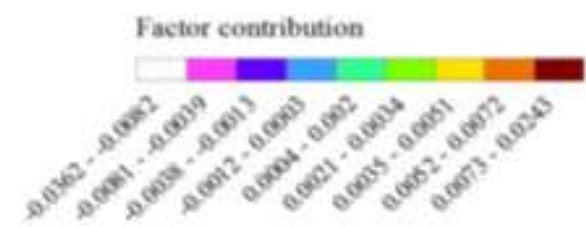




\section{Discussion}

405

\subsection{Relationship between NDVI and multi-scale drought}

406

On longer time scales (6 and 12 months), the area with relatively high correlation coefficients 407 between the NDVI and SPEI in southwest China was extended, with $9.89 \%$ of the total pixels passing the significance test for correlation on the 12-month scale (Fig. 2d), a phenomenon that may result from soil conditions and vegetation type. Southwest China is predominantly mountainous and the vegetation is dominated by trees and scrub, whose roots can draw deep groundwater to resist drought (Davidson et al., 2000; Wu et al., 2018). The correlation between the NDVI and SPEI on different time scales reflects the time sensitivity of vegetation to drought. If the correlation between the NDVI and short time-scale SPEI is higher, vegetation responds to drought faster; if the correlation between the NDVI and long time-scale SPEI is higher, vegetation responds to drought slower, indicating that biomes are more resistant to drought.

The response of vegetation to drought varied with time scale. In this study, we determined that the NDVI had the slowest response to the SPEI-12 and the fastest response to the SPEI-1 (Fig. 2). In previous studies, the response of vegetation to drought has been reported to differ among regions. Compared with other regions in China, vegetation in the Loess Plateau arid zone was the most sensitive to the SPEI (Zhao et al., 2018). The NDVI in North China was more sensitive to drought on short- and medium-term time scales (Zhang et al., 2016). The Mediterranean region was more sensitive to drought on short- and medium-term scales (Gouveia et al., 2016). Vegetation in southwest China is more sensitive to drought on medium- and long-term scales. Therefore, precipitation and evapotranspiration are not the only factors that influence vegetation response to 
drought; other factors include plant species, topographic features, and soil texture.

426

427

428

429

430

431

432

433

434

435

436

437

438

439

440

441

442

443

444

\subsection{Interannual sensitivity response of SPEI to climate factors}

The sensitivity of potential evapotranspiration to meteorological factors has been well studied (Wang et al., 2019; Remus et al., 2019), but the sensitivity of the drought index to meteorological factors has been less studied. Liu et al (2011) demonstrated that the sensitivity of the drought index to meteorological factors was as follows: precipitation $>$ maximum temperature $>$ wind speed > minimum temperature. Zhang et al. (2019) reported that the sensitivity of potential evapotranspiration in the Taohe basin to meteorological factors was as follows: average temperature $>$ precipitation $>$ relative humidity $>$ wind speed $>$ temperature difference $>$ solar radiation. These studies are generally consistent with our findings. Table 1 lists the interannual first-order and total sensitivity coefficients of the SPEI to the six climatic factors. In our study, the total interannual sensitivity of the SPEI to meteorological factors in southwest China was as follows: precipitation $>$ average temperature $>$ average relative humidity $>$ temperature difference $>$ average wind speed $>$ sunshine duration. The abnormal climate driving factors make the ecosystem exceed the climate tolerance threshold and lead to drought disaster, which leads to the increase of vegetation mortality, forest fire and unpredictable changes of vegetation community, and finally has a negative impact on NDVI (Beguería et al., 2014; Gremer et al., 2015).

Table 1 Interannual sensitivity coefficients of the standardized precipitation and evapotranspiration index to climatic factors in southwest China

\begin{tabular}{ccccccc}
\hline Sensitivity coefficient & $\mathrm{S}_{\text {Pre }}$ & $S_{\text {Tem }}$ & $S_{\text {Tmax }- \text { min }}$ & $S_{R h}$ & $S_{W s}$ & $S_{S d}$ \\
\hline First order sensitivity coefficient & 0.25 & 0.01 & 0.05 & 0.12 & 0.10 & 0.01 \\
Total order sensitivity coefficient & 0.79 & 0.55 & 0.35 & 0.54 & 0.22 & 0.10 \\
\hline
\end{tabular}

$44 \overline{5}$ Note: $S_{P r e}, S_{T e m}, S_{T m a x-T m i n}, S_{R h}, S_{W s}$, and $S_{S d}$ represent the sensitivity coefficients of the SPEI to precipitation, mean temperature,

446 temperature difference, mean relative humidity, mean wind speed, and sunshine duration, respectively.

447

448

\subsection{Response of vegetation to climatic and nonclimatic factors}

Our study results indicated that the NDVI had the highest sensitivity to temperature throughout the 
study area (Fig. 4). However, the contribution of mean wind speed to the NDVI was the largest at

450

451

452

453

454

455

456

457

458

459

460

461

462

463

464

465

466

467

468

469

470

471

472

473

474

$0.0008 \mathrm{y}^{-1}$, and the effect of mean wind speed on the interannual trend of the NDVI in the study area was significantly spatially heterogeneous, with the largest effect mainly in eastern Sichuan (Sichuan basin) and southern Guangxi (Guangxi hills) (Fig. 5-e). This may be related to the topographic characteristics of those regions; the Sichuan basin and Guangxi hills are low, the topography is relatively flat, so the climate change is susceptible to wind. And the southern part of Guangxi is close to the sea in the south, which brings water vapor and precipitation through the wind, which in turn affects vegetation growth (Peng et al., 2019; Zha et al., 2016). Human activities had a strong negative contribution to the NDVI in most of Sichuan (Sichuan Basin) and northwestern Yunnan (Hengduan Mountains; Fig. 6c). The large population size and urban expansion in Sichuan province have led to a reduction in vegetation area, so human activities have had a suppressive effect on vegetation growth there, whereas in northwestern Yunnan, which is dominated by plateaus and mountains, the ecology is fragile and vulnerable to the negative effects of human activities (Bounmans et al., 2015). The large difference in the average contributions of the two drivers stems from the short duration and strong effect of human activities on vegetation growth, for example, ecological restoration projects have noticeable effects in the short term, whereas climatic factors have a slow and stable effect on vegetation.

This study quantified the contribution of each driver to vegetation growth in southwest China based on the partial derivative method, but the limited time span may lead to some limitations in our understanding of the effects of different drivers on vegetation dynamics. In addition, plant growth is also influenced by soil type, community characteristics, and other factors. Future research could elucidate the mechanisms of interaction between human activities, climatic factors, and changes in vegetation growth and subdivide and quantify the effects of various nonclimatic factors.

\section{Conclusions}

From 2000 to 2020, the average NDVI in southwest China fluctuated but generally showed a 
slight decreasing trend with a rate of $-0.0001 \mathrm{y}^{-1}$. However, the SPEI showed an increasing trend at a rate of $0.0037 \mathrm{y}^{-1}$, with a nonsignificant wetting trend in the southwest. The NDVI had a delayed

477

478

479

480

481

482

483

484

485

486

487

488

489

490

491

492

493

494

495

496

497

498

499

500

501

response to drought, with a lag time of up to 1 year. The NDVI was most correlated with drought in the central region, followed by the eastern region; the western region had the lowest correlation. Pixels with positive correlations between the NDVI and precipitation, mean temperature, temperature difference, mean relative humidity, mean relative wind speed, and sunshine duration accounted for $31.73 \%, 46.81 \%, 35.49 \%, 25.76 \%, 39.36 \%$, and $39.89 \%$ of the study area, respectively, which indicated that the NDVI was most sensitive to mean temperature, followed by sunshine duration; the NDVI had the lowest sensitivity to mean relative humidity. Therefore, temperature was the most important factor limiting vegetation growth in southwest China. The average contributions of precipitation, mean temperature, temperature difference, mean relative humidity, mean wind speed, and sunshine duration to the NDVI were $0.00029,0.00046,-0.00007$, $0.00007,0.0008$, and $0.00001 \mathrm{y}^{-1}$, respectively. Mean wind speed had the greatest influence on the interannual variation of the NDVI in southwest China, contributing the most to eastern Sichuan (Sichuan Basin). The average contributions of climate factors and human activities to interannual variability in southwest China were 0.00156 and $0.00012 \mathrm{y}^{-1}$, respectively, throughout the study period. Pixels with positive correlations between the NDVI and climate factors and human activities accounted for $80.52 \%$ and $52.49 \%$ of the study area, respectively. Climatic factors had the strongest positive effect on the change in the NDVI.

\section{Author Contribution}

Cuiping Yang: Data curation, Writing-Original draft preparation. Yongqiang Wang, Jiujiang Wu: Conceptualization, Methodology, Software. Xiaoyi Ma: Reviewing and Editing.

\section{Fundings}

This study was financially supported by The National Natural Science Foundation of China, grant 
number 51279167; Distributed Monitoring and Forecasting Technology of Soil Moisture in Irrigation District (No.2017YFC0403202)

\section{Data Availability Statement}

All data generated or analysed during this study are included in this published article.

\section{Conflicts of Interest}

The authors declare no conflict of interest.

\section{References}

Aovk* , B S K , B N S, (2017). Constrained Global Sensitivity Analysis: Sobol' indices for problems in non-rectangular domains. Computer Aided Chemical Engineering, 40:151-156.

Ayana E K, Ceccato P, Fisher J, et al., (2016). Examining the relationship between environmental factors and conflict in pastoralist areas of East Africa. Science of the Total Environment, 557-558:601-611.

Beguería S, Vicente-Serrano S M, Reig F, et al., (2014).Standardized precipitation evapotranspiration index (SPEI) revisited: Parameter fitting, evapotranspiration models, tools, datasets and drought monitoring. Int. J. Climatol, 34: 290-301.

Boumans R, Roman J, Altman I, Kaufman L, (2015). The Multiscale Integrated Model of Ecosystem Services(MIMES): Simulating the interactions of coupled human and natural systems. Ecosyst. Serv., 12: 30-41.

Christopher E, Ndehedehe V G, Ferreira N O, et al., (2019). Hydrological controls on surface vegetation dynamics over West and Central Africa. Ecological Indicators, 103:494-508.

Cong N, Piao S, Chen A, Wang X, Lin X, et al., (2012). Spring vegetation green-up date in China inferred from SPOT NDVI data: a multiple model analysis. Agric For Meteorol, 165:104-113.

Davidson E A, Verchot L V, Cattnio J, et al., (2000). Effects of soil water content on soil respiration in forests and cattle pastures of eastern Amazonia. Biogeochemistry,48: 53-69.

Fu X, Tang C, Zhang X, et al., (2014). An improved indicator of simulated grassland production based on MODIS NDVI and GPP data: A case study in the Sichuan province, China. Ecological Indicators, 40:102-108.

Gong Z N, Zhao S Y, Gu J Z, (2017). Correlation analysis between vegetation coverage and 
Gouveia C M, Trigo R M, Beguería S, et al., (2017). Drought impacts on vegetation activity in the Mediterranean region: An assessment using remote sensing data and multi-scale drought indicators. Global and Planetary Change,151: 15-27.

Gremer J R, Bradford J B, Munson S M, Duniway M C, et al., (2015). Desert grassland responses to climate and soil moisture suggest divergent vulnerabilities across the southwestern United States. Glob. Chang. Biol, 21: 4049-4062.

Han Z, Song W, (2019). Spatiotemporal variations in cropland abandonment in the Guizhou-Guangxi karst mountain area, China. Journal of Cleaner Production, 238:1-15.

Huang W, Ho H C, Peng Y, et al., (2016). Qualitative risk assessment of soil erosion for karst

Keisling B A, Castañeda I S, Brigham G J, et al., (2017). Hydrological and temperature change in Arctic Siberia during the intensification of Northern Hemisphere Glaciation. Earth and Planetary Science Letters,457:136-148.

Li G, Zhang F, Jing Y, Liu Y, Sun G, (2017a). Response of evapotranspiration to changes in land use and land cover and climate in China during 2001-2013. Sci.Total. Environ. 596:256-265.

Li L N, (2009). Study on spatial Variation of Temperature and Precipitation and its Correlation with NDVI in Shaanxi Province. Shaanxi: Doctoral Dissertation of Northwest University, 56-60.

Lizaga I, Gaspar L, Quijano L, et al., (2018). NDVI, ${ }^{137} \mathrm{Cs}$ and nutrients for tracking soil and vegetation development on glacial landforms in the Lake Parón Catchment (Cordillera Blanca, Perú). The Science of the total environment,651:250-260.

Li Z, Chen Y N, Li W H, Deng H J, Fang G H, (2015). Potential Impacts of Climate Change on Vegetation Dynamics in Central Asia. Geophys. Res. Atmos., 120, 2045-2057.

Liu X F, Zhu X F, Pan Y Z, Li S S, et al., (2016). V egetation dynamics in Qinling-Daba Mountains in relation to climate factors between 2000 and 2014. Geogr. Sci. 26:45-58.

Li X Y, Li Y, Chen A P, et al., (2019).The impact of the 2009/2010 drought on vegetation growth and terrestrial carbon balance in Southwest China. Agricultural and Forest Meteorology, 269:239-248. 
Liu C M, Zhang D, et al., (2011). Spatial-temporal variation of sensitivity to potential evapotranspiration over China. Acta geographica sinica,66(5):579-588.

Mao D H, Wang Z M, Han J X, et al., (2012). Spatio-temporal Pattern of Net Primary Productivity and Its Driven Factors in Northeast China in 1982-2010. Scientia Geographica Sinica, 32(9): 1106-1111.

Meng D, Mo X, (2012). Assessing the effect of climate change on mean annual runoff in the Songhua River basin, China. Hydrological Processes, 26(7):1050-1061.

Mo K, Chen Q, Chen C, et al., (2019). Spatiotemporal variation of correlation between vegetation cover and precipitation in an arid mountain-oasis river basin in northwest China. Journal of Hydrology, 574:138-147.

Mu S J, Yang H F, Li J L, Chen Y Z, et al., (2013). Spatio-temporal dynamics of vegetation coverage and its relationship with climate factors in Inner Mongolia, China. J. Geogr. Sci., $23,231-246$.

Nijssen B, Lettenmaier D P, Mu X, et al., (2016). Drought in the Pacific Northwest, 1920-2013. Journal of hydrometeorology, 17(9):2391-2404.

Peng W, Kuang T, Tao S, (2019). Quantifying influences of natural factors on vegetation NDVI changes based on geographical detector in Sichuan, western China. Journal of Cleaner Production, 233: 353-367.

Qu S, Wang L, Lin A, et al., (2018). What drives the vegetation restoration in Yangtze River basin, China: Climate change or anthropogenic factors? Ecological Indicators, 90:438-450.

Remus B, A Prvlie, et al., (2019). Spatio-temporal changes of the climatic water balance in Romania as a response to precipitation and reference evapotranspiration trends during 1961-2013. Catena,172:295-312.

Ruspini E H, (1965). A new approach to clustering. Information and Control, 1969, 15(1):22-32.

Shi S Y, Yu J J, Wang F, et al., (2020). Quantitative contributions of climate change and human activities to vegetation changes over multiple time scales on the Loess Plateau. Science of The Total Environment, 755:1-14.

Turco M, Levin N, Tessler N, et al., (2016). Recent changes and relations among drought, vegetation and wildfires in the Eastern Mediterranean: The case of Israel. Global \& Planetary 
Change, 151:28-35.

Vicente-Serrano M, Beguería S, López-Moreno J I, (2010). A multiscalar drought index sensitive to global warming: the standardized precipitation evapotranspiration index. Journal of Climate,23(7) : 1696-1718.

Wang Z, Ye A, Wang L, et al., (2019). Spatial and temporal characteristics of reference evapotranspiration and its climatic driving factors over China from 1979-2015. Agricultural Water Management, 213:1096-1108.

Wu X C, Liu H Y, Li X Y, et al., (2018). Differentiating drought legacy effects on vegetation growth over the temperate Northern Hemisphere. Global Change Biology, 24: 504-516.

Yang H, Yang D, (2012). Climatic factors influencing changing pan evaporation across China from 1961 to 2001. Journal of Hydrology, (s414/415):184-193.

Yan Y, Liu X, Wen Y, et al., (2019). Quantitative analysis of the contributions of climatic and human factors to grassland productivity in northern China. Ecological indicators, 103:542-553.

Yao R, Wang L C, Huang X, et al., (2018). Less sensitive of urban surface to climate variability than rural in Northern China. Sci. Total Environ. 629:650-660.

Zha B, Wei S A, (2016). Abandoned cropland: Patterns and determinants within the Guangxi Karst Mountainous Area, China. Applied Geography, 122:245-256.

Zhang H, Fan J, Wang J, et al., (2018). Spatial and temporal variability of grassland yield and its response to climate change and anthropogenic activities on the Tibetan Plateau from 1988 to 2013. Ecological Indicators, 95:141-151.

Zhang B, Wang Z, Chen G, et al., (2017). A Sensitivity Study of Applying a Two-Source Potential Evapotranspiration Model in the Standardized Precipitation Evapotranspiration Index for Drought Monitoring.Land Degradation \& Development,28(2):783-793.

Zhang J, Qiao Z, et al., (2016). Assessing the remotely sensed Drought Severity Index for agricultural drought monitoring and impact analysis in North China. Ecological Indicators, $143: 387-396$.

Zhang Q, Qi T Y, Singh V P, Chen Y D, Xiao M Z, (2015). Regional frequency analysis of droughts in China: a multivariate perspective. Water Resources Management, 2015,29(6): 
$1767-1787$.

619 Zhang Y, Zhang C, Wang Z, Chen Y, et al., (2016). Vegetation dynamics and its driving forces from climate change and human activities in the Three River Source Region, China from 1982 to 2012. Sci. Total. Environ. 563, 210-220.

622 Zhao A, Zhang A, Liu H, Liu Y, Wang H, Wang D, (2017). Spatiotemporal variation of vegetation coverage before and after implementation of Grain for Green Project in the Loess Plateau. J Nat Resourc 32:449-460.

625

Zhao A Z, Zhang A B, Cao S, et al., (2018). Responses of vegetation productivity to multi-scale drought in Loess Plateau, China. Catena, 163: 165-171.

Zhao G J, Mu X M, Jiao J Y, Gao Peng, et al., (2018). Assessing response of sediment load variation to climate change and human activities with six different approaches. The Science of the total environment,639:773-784.

630 Zhao J, 1997. Physical Geography of China. 4th Ed. Beijing: Higher Education Press.

631 Zhu G, Qin D, Liu Y et al, (2017). Accuracy of TRMM precipitation data in the southwest monsoon region of China.Theoretical and Applied Climatology,129(1/2):353-362. 